\title{
The Inherent Building Energy-Cost Relationship: An analysis of thirty Melbourne case studies
}

\author{
Yu Lay Langston and Craig Langston (Mirvac School of Sustainable Development, Bond University, Australia)
}

\begin{abstract}
This study investigates the energy and cost performance of thirty recent buildings in Melbourne, Australia. Commonly, building design decisions are based on issues pertaining to construction cost, and consideration of energy performance is made only within the context of the initial project budget. Even where energy is elevated to more importance, operating energy is seen as the focus and embodied energy is nearly always ignored. For the first time, a large sample of buildings has been assembled and analysed to improve the understanding of both energy and cost performance over their full life cycle. The aim of this paper is to determine the relationship between energy and cost using regression analysis for a range of building functional types. The conclusion is that energy and cost are strongly correlated, independent of building area, and equations are presented for future modelling of energy using cost as the independent variable.
\end{abstract}

Keywords: energy-cost relationship, correlation, optimisation, energy prediction, Melbourne.

\section{INTRODUCTION}

Energy has become a significant issue worldwide. Greenhouse gas emissions (GGE) and the perceived threat of climate change (caused by phenomena such as global warming and ozone depletion) is identified by Beggs (2002; p.10) as driving, "more than any other issue", change in energy consumption attitudes. Since the energy crisis of the mid-1970s attention has been directed towards strategies that lower operating energy demand (Robertson, 1991), yet it has been only recently that the impact of energy embodied in building materials themselves has come under scrutiny. Despite this trend, the routine analysis of embodied energy remains absent (Treloar et al., 2002).

Proper energy analysis during the design process can no longer be simply overlooked. ASEC (2001; p.100) indicate that "total energy use has doubled [in Australia] over the last 25 years [...] at a faster rate than GDP". The rationale behind this paper firmly lies with the perceived lack of integration of energy analysis into current practice. Capital cost still remains the primary criterion for building procurement decisions (Brown and Yanuck, 1985; Langston, 1991; Bull, 1992), while other criteria are given less significance either due to a narrow myopic focus (Ashworth, 1988) or because a suitable multi-criteria technique has not been satisfactorily identified (van Pelt et al., 1990).

Energy analysis is costly, time-consuming and, when undertaken during the design phase, usually based on a large number of assumptions (Verbeek and Wibberley, 1996). Even so, it is likely to produce conflicting advice to that generated from capital cost estimates (Arnold, 1993). This occurs because energy analysis takes a long-term view, one that introduces multiple stakeholders and wider social concerns, rather than merely reflecting immediacy and profit-centred objectives. It has been argued over many years (e.g. Stone, 1960; Kirk and Dell'Isola, 1995; Flanagan and Norman, 1983; Langston and Lauge-Kristensen, 2002) that costs should also be accounted over a longer time span. Known as life cycle costs (LCCs) or whole life-costing (WLC), these comprise both initial (capital) and recurrent (operating) components that can be aggregated to give a more realistic picture of the total expenditure commitment (Fuller, 1982).

The problem essentially is how two criteria, one measured in financial terms and the other in pure energy terms, can ever be reconciled to provide clear building design guidance. In fact, any comparison of particular material choices will usually indicate that cost and energy ratios vary widely (Irurah and Holm, 1999). Yet at the level of an entire building this differential is expected to be less - a view that is supported to some extent by the manner in which embodied energy intensities are often determined (i.e. from national input-output financial tables) and operating energy interpreted (i.e. incurred cost).

Embodied energy is defined as the energy used in building construction, including all the upstream processes such as raw material mining, manufacture, packaging and transportation to site. Operating energy is defined as the energy used in maintaining a comfortable indoor environment, including heating, ventilation and air conditioning, as well as lighting, power for equipment and other recurrent energy requirements. Both are measured in primary energy terms.

Capital cost is defined as the expenditure used in building construction, including labour, materials, plant and overheads, but often excluding contingencies, professional fees, land acquisition costs and goods and services tax, which are all treated as purchase costs. Operating cost is defined as the expenditure required to clean, repair, maintain, replace and otherwise manage proper usage of the building over its life, including the cost of energy provision. All costs need to be expressed in real terms (constant dollars).

If there is an inherent relationship between energy and cost that can be exploited to enable better design solutions to be identified, then it should be possible to quantify energy directly from a life-cost investigation. The outcomes will naturally be dependent on the chosen time horizon for the study but will simplify the process of embodied energy calculation (in particular) that to date has proved elusive to common practice. Nevertheless, it should be remembered that the biggest cost to an organisation is usually the salaries of its employees, and that this matter has no real connection with energy demand. Salaries can be shown to represent more than $80 \%$ of life-costs (Evans et al. 1998; Langston 2005). For the purposes of this study, staff salaries and related occupancy costs are ignored.

The purpose of this paper is to discover the extent of any relationship between energy and cost, using regression analysis, for a range of building types in Melbourne, Australia. From this information, a better understanding of facilities performance can 
be obtained, leading to further insight into the relationship between energy and cost. The structure of this paper is to review previous research findings, to outline the method adopted in this research, to analyse the results, and to make observations and draw conclusions for practice.

\section{BACKGROUND}

Previously published research about the relationship between energy and cost is largely confined to a few studies (Costanza, 1980; Costanza, 1984; Lavine and Butler, 1982; Oka et al., 1993; Ding, 2004). These are explored in more detail below.

Costanza (1980) adapt input-output analysis to calculate the total (direct plus indirect) energy required to produce goods and services in the U.S. economy. He states that usually the energy required to produce labour and government services and the solar energy input to the economy is overlooked. The omission can be traced to the assumption that traditional primary energy factors of economic production (land, labour and capital) are independent. He makes the strong case that these input factors are not independent and that energy is required for their production. Embodied energy intensities can be calculated in this case by using input-output data.

The results of such an analysis show that that there is a strong correlation between embodied energy and dollar values for a 92-sector U.S. economy if the energy required to produce labour and government services is included. Costanza (1980; p.1224) concludes his research with the observation that "the most important implication is that the physical dimensions of economic activity are not separable from limitations of energy supply". He continues by arguing that the universally-appealing notion of unlimited economic growth with reduced energy consumption must be firmly put to rest beside the equally appealing but impossible idea of perpetual motion. It is easy to get a "free lunch" by looking only at small parts of the system in isolation, but when the entire system is analysed it becomes clear that the cost of "your lunch" is just being transferred to another part of the system.

Costanza (1984) reaffirms his earlier work. Input-output models of the economy, modified to include households and government as endogenous sectors, are used to calculate each sector's direct plus indirect (embodied) energy consumption based on estimates of the distribution of direct energy inputs to the sectors. Dollar value of sector output is highly correlated with this energy indicator. Therefore an economy can be said to operate on an energy theory of value since it can be scientifically proven to be proportional to an appropriate energy indicator.

Lavine and Butler (1982; p.2) determine from their research that the dollar value of economic output is accurately predicted by embodied energy figures. They quote other studies by Brown and Lugo, Kemp et al. and Hall et al. (not separately cited), as well as Costanza, undertaken in the 1980s. In all cases strong correlations between the embodied energy value of inputs to an economy and the monetary value of the economy's output are shown. They conclude:

"Since the global system operates at approximately steady state, the net work output of the global system must equal the sunlight energy input. [...] This 'work output' interpretation of embodied energy suggests the hypothesis that embodied energy values can predict economic values. The reasoning is that economic value is achieved in direct proportion to economic work, and economic work is in direct proportion to the work output achieved with the use of resource inputs to the economy. Because embodied energy is a measure of such work output, embodied energy also may be a measure of economic value."

Lavine and Butler (1982) also argue that embodied energy values can provide a consistent means for pricing environmental factors. Such prices may facilitate a more comprehensive consideration of the economic effects of many kinds of environmental policy decisions.

The most relevant previous research, and most recent, is Oka et al. (1993). The total energy consumption and environmental pollution caused by construction are quantified using input-output data (referred to as the Inter-Industry Relations Table). Six office buildings in Japan, varying from $1,502 \mathrm{~m}^{2}$ to $216,000 \mathrm{~m}^{2}$, are evaluated. The major results are:

- total energy consumption caused by construction of office buildings is $8-12 \mathrm{GJ} / \mathrm{m}^{2}$ of floor area

- $\quad \mathrm{CO}_{2}$ production is $750-1140 \mathrm{~kg}, \mathrm{SO}$ and $\mathrm{SO}_{2}$ production is $720-1430 \mathrm{~g}, \mathrm{NO}$ and $\mathrm{NO}_{2}$ production is $700-1140 \mathrm{~g}$, and dust is $70-130 \mathrm{~g}$ (per $\mathrm{m}^{2}$ of floor area)

- the construction cost $/ \mathrm{m}^{2}$ of floor space is proportional to the energy consumption and production of pollutants

- $\quad$ structural work is shown to be high in energy consumption and $\mathrm{CO}_{2}$ exhausted per unit cost of construction, industrial waste exhausted in finishing work is higher than the other two categories of work (structure and equipment), while equipment work is shown to be relatively low in energy consumption, $\mathrm{CO}_{2}, \mathrm{NO}, \mathrm{NO}_{2}$ and industrial waste produced

They find that the average values of energy consumption and pollutants released due to the construction of the six buildings is $32 \mathrm{MJ} / 1000$ yen for energy consumption, $3.0 \mathrm{~kg} / 1000$ yen for $\mathrm{CO}_{2}$ production, $3.1 \mathrm{~g} / 1000$ yen for $\mathrm{NO}$ and $\mathrm{NO}_{2}$ production, and 1.0 $\mathrm{g} / 1000$ yen for industrial waste production. Although correlation coefficients are not shown, all cost, energy and pollutant relationships reflect a tight linear pattern.

Research completed by Ding (2004) concerns the use of multicriteria analysis as a selection tool for sustainable development. She obtained detailed information relating to twenty educational (high school) projects in New South Wales, Australia. Among this data are floor area, embodied energy (construction), operating energy (including the energy embodied in forecast maintenance and repair work), capital (construction) cost and operating cost. All data are based on real performance where possible. The mean initial embodied energy across all projects is $8.05 \mathrm{GJ} / \mathrm{m}^{2}$, while the mean operating energy is $40.89 \mathrm{GJ} / \mathrm{m}^{2}$ or $0.68 \mathrm{GJ} / \mathrm{m}^{2} /$ annum (this falls to $32.92 \mathrm{GJ} / \mathrm{m}^{2}$ or $0.55 \mathrm{GJ} / \mathrm{m}^{2} /$ annum when recurrent embodied energy is removed). Floor area is measured as gross floor area $\left(G^{\prime} A^{1}\right)$. The mean capital cost (A $\left.\$ 2002\right)$ across all projects is $\$ 1,360 / \mathrm{m}^{2}$, while the mean operating cost is $\$ 1,946 / \mathrm{m}^{2}$ or $\$ 32.43 / \mathrm{m}^{2} /$ annum. The cost of maintenance and repair cannot be extracted from the data. Floor area is again measured as GFA.

\section{METHOD}

The characteristics of the relationship between energy and cost require further study. In particular, it is important to determine whether the relationship is robust and independent of the influence

${ }^{1} \mathrm{GFA}$ is defined as the fully enclosed floor area, measured to the internal line of external walls, plus the unenclosed covered area measured to the external face of external walls, at all floor levels of the building. 
of building size. The selected research method adopted in this paper is sampling via case studies. Case study is an ideal methodology when a holistic in-depth investigation is needed (Feagin et al., 1991). It has been used in varied investigations, particularly in sociological studies but increasingly in construction. The procedures are robust, and when followed the approach is as well developed and tested as any in the scientific field. Whether the study is experimental or quasi-experimental, the data collection and analysis methods are known to hide some details. Case studies, on the other hand, are designed to bring out the details from the viewpoint of the participants by using multiple sources of data (Tellis, 1997).

The data for the research are drawn from actual case studies obtained courtesy of the Melbourne office of Davis Langdon Australia, a large national quantity surveying practice. Case studies are located across Greater Melbourne and are specifically intended to reflect a broad range of functional purpose.

Capital cost data and floor areas are obtained directly from the elemental cost plans prepared by Davis Langdon Australia. Embodied energy intensities are estimated from the composite items of work listed in these documents using the input-outputbased hybrid method (Treloar, 1998; Crawford, 2004). Operating cost is estimated from reasonable cycles for future maintenance and replacement work using LIFECOST ${ }^{\mathrm{TM}}$ software. Operating energy is based on data obtained from the Property Council of Australia for Melbourne office buildings, adjusted to allow for extended opening hours for other functional uses. All costs are adjusted and expressed in fourth quarter 2006 dollars using published building price indices (BPI) also supplied by Davis Langdon Australia. None of these data have a direct relationship with GFA, but an indirect relationship (i.e. bigger buildings use more energy and cost more money) is implied.
Thirty recent Melbourne projects are used as case studies. These projects represent diverse functions including provision of office workspace, health facilities, residential accommodation, teaching and laboratory space, retail, hotel accommodation and a number of specialist uses. Projects comprise both new construction (73.3\%) and redevelopment (26.7\%). So-called residential projects, comprising apartment buildings and aged care facilities, account for $23.3 \%$ of the case studies, and the remainder are constructed for various other commercial uses. One-third of the case studies are hospitals.

Projects range from 1997 to 2004, and vary in floor area from 249 $\mathrm{m}^{2}$ to $18,821 \mathrm{~m}^{2}$ GFA. The mean floor area is $3,749 \mathrm{~m}^{2}$ (coefficient of variation of $110.75 \%$ ). They comprise a wide range of materials and standards, some are air-conditioned and some not, some have fire sprinkler systems, some have loose furniture and special equipment, and some have substantial external works.

This mix decreases the likelihood that projects exhibit similarities in energy and cost performance. Economies of scale also play a part in larger projects, which tend to have lower unit costs than identical designs of smaller size. The mix is therefore effectively random, enabling a range of statistical techniques to be applied to the sample.

Table 1 lists the case studies used in this research by building type. Case studies are identified by a numerical code, as the name and location of projects needs to be kept confidential (this is a nonnegotiable agreement made between the researchers and Davis Langdon Australia).

Data supplied by Davis Langdon Australia comprise GFA and elemental capital costs based on hundreds of abbreviated measured quantities extracted from design cost plans. The full

Table 1: Case study base information

\begin{tabular}{|c|c|c|c|}
\hline $\begin{array}{l}\text { Building } \\
\text { ID }\end{array}$ & Year & Building Type & $\begin{array}{r}\text { Gross Floor } \\
\text { Area }\left(\mathrm{m}^{2}\right)\end{array}$ \\
\hline $\begin{array}{l}1 \\
2 \\
3 \\
4 \\
5 \\
6 \\
7 \\
8 \\
9 \\
10 \\
11 \\
12 \\
13 \\
14 \\
15 \\
16 \\
17 \\
18 \\
19 \\
20 \\
21 \\
22 \\
23 \\
24 \\
25 \\
26 \\
27 \\
28 \\
29 \\
30\end{array}$ & $\begin{array}{l}2003 \\
2004 \\
2004 \\
2000 \\
2003 \\
2003 \\
2003 \\
2003 \\
2004 \\
2003 \\
2004 \\
2004 \\
2004 \\
2001 \\
2001 \\
2000 \\
1999 \\
2000 \\
1998 \\
1998 \\
1998 \\
1999 \\
1999 \\
1999 \\
1999 \\
1999 \\
1999 \\
1998 \\
1998 \\
1997 \\
\end{array}$ & $\begin{array}{l}\text { Residence (new) } \\
\text { Residence (new) } \\
\text { Residence (new) } \\
\text { Office (new) } \\
\text { Health Centre (redevelopment) } \\
\text { Hospital (new) } \\
\text { Residence (new) } \\
\text { Information Centre (new) } \\
\text { Hospital (redevelopment) } \\
\text { Hospital (redevelopment) } \\
\text { Library (new) } \\
\text { Civic Hall (new) } \\
\text { Primary School (new) } \\
\text { Residence (new) } \\
\text { Hospital (redevelopment) } \\
\text { Hospital (new) } \\
\text { Hotel (redevelopment) } \\
\text { Car Parking Station (new) } \\
\text { Hospital (new) } \\
\text { Health Centre (new) } \\
\text { Hospital (new) } \\
\text { Hotel (new) } \\
\text { Residence (redevelopment) } \\
\text { University Building (new) } \\
\text { Office (new) } \\
\text { Hospital (redevelopment) } \\
\text { Hospital (redevelopment) } \\
\text { University Building (new) } \\
\text { Residence (new) } \\
\text { Hospital (new) }\end{array}$ & $\begin{array}{r}1,409 \\
450 \\
1,791 \\
2,543 \\
528 \\
6,761 \\
328 \\
1,223 \\
3,278 \\
3,760 \\
249 \\
625 \\
2,696 \\
2,790 \\
5,677 \\
378 \\
652 \\
5,412 \\
4,281 \\
787 \\
1,159 \\
12,930 \\
18,821 \\
10,565 \\
4,704 \\
1,345 \\
5,940 \\
2,502 \\
5,223 \\
3,649 \\
\end{array}$ \\
\hline
\end{tabular}

Source: Davis Langdon Australia (Melbourne Office) 
project cost is presented, including Preliminaries, Site Works and External Services, and Special Provisions (such as allowances for loose furniture and equipment), but excluding contingencies, professional fees, land acquisition costs and goods and services tax. All other data are estimated using embodied energy models, promulgated operating energy targets (for Melbourne), expected maintenance and replacement cycles, and other operational assumptions.

Embodied energy, including both initial and recurrent embodied energy, is determined using a sophisticated spreadsheet model. The model is an input-output-based hybrid method that embraces both process analysis data (where it is available) supplemented with the input-output data from published government statistics (1996-1997 financial year), extracted and compiled at Deakin University by Dr Graham Treloar and Dr Robert Crawford. Looking at embodied energy, $41.65 \%$ of the overall calculation used process analysis data, varying between $25.56 \%$ and $62.60 \%$ across the thirty case studies (coefficient of variation equals $15.89 \%)$.

Operating energy is estimated using a simple model based on occupancy hours per year and 'good practice guidelines' for new buildings in Melbourne (PCA, 2001) $)^{2}$. The latter translates to 0.56 $\mathrm{GJ} / \mathrm{m}^{2}$ net lettable area per year (or $155.5 \mathrm{kWh} / \mathrm{m}^{2} /$ annum),

${ }^{2}$ Note that the good practice guidelines were used in preference to the new building design target (PCA, 2001) in this study. The latter is a $28.5 \%$ reduction from the former, yet in the short-term this is unlikely to be achieved for the general run of projects except those that are specifically designed as energy efficient. comprising $70 \%$ electricity and $30 \%$ gas (where gas supply is present), or $100 \%$ electricity (where no gas supply is present). Delivered energy is converted to primary energy using a factor of 2.72 for electricity (based on $80 \%$ brown coal at efficiency $=3.4$ and $20 \%$ green power at efficiency=1) and 1.4 for gas. Office buildings assume nominal occupancy of 2,500 hours/annum (equivalent to $8 \mathrm{am}$ to $6 \mathrm{pm}$ Monday to Friday) as defined in PCA (2001). Hospitals, hotels, residential accommodation and car parking facilities are assumed to operate for 5,460 hours/annum (equivalent to $8 \mathrm{am}$ to $11 \mathrm{pm}$ Monday to Sunday), and this translates to an occupancy factor of 2.18 compared to office buildings.

Embodied and operating energy data are provided in Table 2. It is important to note that although an implied relationship exists between energy and GFA (i.e. bigger buildings use more energy both to construct and operate), the derivation of energy has no direct relationship to area. Embodied energy is modelled using energy intensities applied to hundreds of work items, and is effectively the true embodied energy of the project using the most comprehensive method available. Alternatively, operating energy is modelled more simplistically, and is a function of operating hours and occupancy profile in relation to useable floor areas. Neither embodied nor operating energy are directly computed from GFA.

Capital costs are converted to fourth quarter 2006 prices using a BPI provided by Davis Langdon Australia. Otherwise no adjustment to capital costs is undertaken and all unit rates are taken as correct and reflective of the project given applicable market conditions at the time. The BPI for fourth quarter 2006 is 175.0 (later indices were not used as they were still forecasts at the time of analysis).

Table 2: Case study energy summary

\begin{tabular}{|c|c|c|c|c|}
\hline $\begin{array}{l}\text { Building } \\
\text { ID }\end{array}$ & $\begin{array}{l}\text { Floor Area } \\
\left(\mathrm{m}^{2} \text { GFA) }\right.\end{array}$ & $\begin{array}{r}\text { Total } \\
\text { Initial (GJ) }\end{array}$ & $\begin{array}{r}\text { lied Energy } \\
\text { Recurrent } \\
(G J / y r)\end{array}$ & $\begin{array}{r}\text { Other } \\
\text { Operating } \\
\text { Energy (GJ/yr) }\end{array}$ \\
\hline 1 & 1,409 & 26,741 & 370 & 2,448 \\
\hline 2 & 450 & 9.571 & 148 & 979 \\
\hline 3 & 1,791 & 36,679 & 429 & 2,924 \\
\hline 4 & 2,543 & 60,326 & 550 & 2,504 \\
\hline 5 & 528 & 9,558 & 103 & 584 \\
\hline 6 & 6,761 & 154,157 & 1,688 & 12,156 \\
\hline 7 & 328 & 6,815 & 119 & 546 \\
\hline 8 & 1,223 & 21,397 & 279 & 1,299 \\
\hline 9 & 3,278 & 77,893 & 785 & 6,771 \\
\hline 10 & 3,760 & 96,512 & 1,003 & 7,427 \\
\hline 11 & 249 & 5,991 & 91 & 263 \\
\hline 12 & 625 & 15,696 & 186 & 664 \\
\hline $1 \overline{3}$ & 2,696 & 49,445 & 695 & 2,148 \\
\hline 14 & 2,790 & 62,048 & 947 & 6,115 \\
\hline 15 & 5,677 & 134,281 & 2,376 & 10,751 \\
\hline 16 & 378 & 9,009 & 100 & 740 \\
\hline 17 & 652 & 10,405 & 309 & 1,420 \\
\hline 18 & 5,412 & 105,937 & 149 & 3,551 \\
\hline 19 & 4,281 & 112,160 & 1,345 & 8,657 \\
\hline 20 & 787 & 18,322 & 204 & 821 \\
\hline 21 & 1,159 & 28,008 & 436 & 2,218 \\
\hline 22 & 12,930 & 286,656 & 3,943 & 29,947 \\
\hline 23 & 18,821 & 260,255 & 4,354 & 37,177 \\
\hline 24 & 10,565 & 263,068 & 2,839 & 11,564 \\
\hline 25 & 4,704 & 121,541 & 1,226 & 4,998 \\
\hline 26 & 1,345 & 24,983 & 403 & 2,578 \\
\hline 27 & 5,940 & 149,738 & 1,332 & 11,615 \\
\hline 28 & 2,502 & 57,218 & 607 & 2,593 \\
\hline 29 & 5,223 & 96,058 & 1,602 & 9,568 \\
\hline 30 & 3,649 & 78,622 & 775 & 6,973 \\
\hline
\end{tabular}


Operating costs, on the other hand, are estimated using LIFECOST ${ }^{\mathrm{TM}}$ software provided by Computerelation Australia Pty Limited. Maintenance and replacement cycles are determined using personal experience together with a number of useful references (e.g. Dell'Isola and Kirk, 1995), and priced by original unit rates with a suitable allowance for removal and disposal costs where applicable. All costs are adjusted to fourth quarter 2006 as before described.

Capital and operating cost data are provided in Table 3. It is important to note that although an implied relationship exists between cost and GFA (i.e. bigger buildings cost more to construct and operate), the derivation of cost has no direct relationship to area. Capital cost is estimated by the quantity surveyor based on hundreds of work items, and is effectively the real cost of the project. Alternatively, operating cost is modelled based also on hundreds of work items, and is a function of component life expectancies, cleaning and repair cycles. Neither capital nor operating cost are directly computed from GFA.

For all operating costs and operating energy, including recurrent embodied energy, a one-hundred-year time horizon has been assumed.

\section{RESULTS}

Base data are analysed in Langston and Langston (2007). The relationship between total life cycle energy (embodied + operating) and total life cycle cost (capital + operating) leads to a regression line of $y=0.0137 x$, where $y$ equals total life cycle energy and $x$ equals total life cycle cost. As with all following correlations, the $y$-intercept has been assumed at zero (i.e. no energy, no cost). Figure 1 shows the regression results for the Melbourne buildings.

The correlation between initial embodied energy and capital cost leads to a regression line of $y=0.0071 x$. The Melbourne case studies are shown in Figure 2.

This is an important relationship for the prediction of embodied energy based on construction cost estimates. Provided costs are expressed in fourth quarter 2006 terms, the embodied energy can be derived in minimal time using the constant (gradient) of 0.0071 . The reliability of this constant is investigated in Langston and Langston (2008).

Operating energy and operating cost, calculated over a onehundred-year time horizon, leads to a regression line of $y=0.0150 x$, as shown graphically in Figure 3 . In all investigated cases, the relationships between energy and cost are clearly linear, and require no more complex regression method.

\section{VARIABLE DEPENDENCY}

An obvious criticism of this research is that both energy and cost are proxies for building area, and therefore all that has been shown is that bigger buildings use more energy and cost more money. In order to determine the 'goodness of fit' $\left(r^{2}\right)$ for each relationship it is first necessary to remove area from the comparison. This can be done in one of two ways.

The first way is to express energy and cost as unit rates (i.e. energy $/ \mathrm{m}^{2}$ and cost $/ \mathrm{m}^{2}$ ). The influence of building size is

Table 3: Case study cost summary

\begin{tabular}{|c|c|c|c|c|}
\hline \multirow{2}{*}{$\begin{array}{l}\text { Building } \\
\text { ID }\end{array}$} & \multirow{2}{*}{$\begin{array}{r}\text { Floor Area } \\
\left(m^{2} \text { GFA }\right)\end{array}$} & \multirow{2}{*}{$\begin{array}{r}\text { Capital Cost } \\
(\$ 2006)\end{array}$} & \multicolumn{2}{|c|}{ Operating Cost/yr (\$2006) } \\
\hline & & & $\begin{array}{c}\text { Recurrent } \\
\text { Expenditure }\end{array}$ & $\begin{array}{l}\text { Energy } \\
\text { Expenditure }\end{array}$ \\
\hline 1 & 1,409 & $2,999,243$ & 75,221 & 33,654 \\
\hline 2 & 450 & $1,198,625$ & 44,716 & 13,462 \\
\hline 3 & 1,791 & $3,881,208$ & 102,215 & 43,189 \\
\hline 4 & 2,543 & $6,321,146$ & 293,590 & 42,622 \\
\hline 5 & 528 & 832,897 & 34,125 & 8,033 \\
\hline 6 & 6,761 & $20,213,443$ & 790,532 & 211,057 \\
\hline 7 & 328 & 575,722 & 45,054 & 8,301 \\
\hline 8 & 1,223 & $1,984,097$ & 106,580 & 17,863 \\
\hline 9 & 3,278 & $10,932,154$ & 308,775 & 112,286 \\
\hline 10 & 3,760 & $13,188,297$ & 379,602 & 119,721 \\
\hline 11 & 249 & 577,654 & 27,142 & 3,622 \\
\hline 12 & 625 & $1,710,606$ & 65,176 & 9,129 \\
\hline 13 & 2,696 & $4,140,979$ & 265,684 & 29,723 \\
\hline 14 & 2,790 & $7,901,075$ & 456,106 & 103,254 \\
\hline 15 & 5,677 & $16,603,374$ & 750,830 & 212,207 \\
\hline 16 & 378 & $1,174,502$ & 60,533 & 15,183 \\
\hline 17 & 652 & $1,325,701$ & 107,333 & 25,804 \\
\hline 18 & 5,412 & $5,857,972$ & 207,995 & 60,434 \\
\hline 19 & 4,281 & $12,754,657$ & 501,092 & $\begin{array}{r}191,499 \\
\end{array}$ \\
\hline 20 & 787 & $1,806,207$ & 97,070 & 15,450 \\
\hline & 1,159 & $3,042,888$ & 213,702 & 48,087 \\
\hline & 12,930 & $43,838,966$ & $1,609,751$ & 539,706 \\
\hline 23 & 18,821 & $41,392,112$ & $1,670,800$ & 792,257 \\
\hline 24 & 10,565 & $36,750,343$ & $1,043,406$ & 215,991 \\
\hline 25 & 4,704 & $16,328,325$ & 597,484 & 90,831 \\
\hline 26 & 1,345 & $3,143,639$ & 160,966 & 54,933 \\
\hline 27 & 5,940 & $19,778,684$ & 612,987 & 247,515 \\
\hline 28 & 2,502 & $5,796,121$ & 238,294 & 47,947 \\
\hline-0 & 5,223 & $13,119,590$ & 660 , & \\
\hline & 3,64 & 9,03 & 393,95 & 15 \\
\hline
\end{tabular}


therefore limited to issues relating to economies of scale, where bigger buildings will tend to have slightly lower unit rates due to efficiencies caused by the larger scope of works. But this method has the disadvantage of clustering (bunching) the project data around the average, making any correlation specific to the effect of the economies of scale only. For this reason this method is not recommended as leading to a practical and valid outcome.

The second way is to compare energy with area (and cost with area) and then compare the residuals of both analyses, thus eliminating the GFA trends in each case. Thus, the underlying relationship between energy and cost is exposed after eliminating all dependency (whether direct or indirect) on building area.

Residual (or error) represents unexplained variation after fitting a regression model. It is the difference (or left over) between the observed value of the variable and the value suggested by the regression model. By comparing energy and GFA (or cost and GFA), the residuals for each represent the unexplained variation, and enable the independent relationship between energy and cost to be tested.

It is obvious that energy or cost is positively correlated with building size, and confirms the simple conclusion that bigger buildings demand more energy and cost more to construct or operate. The analysis of residuals, however, shows that even after building area is eliminated, there is still a strong relationship between energy and cost. The original regression exercises provide a model for predicting energy performance based on cost, while the residual regression exercises demonstrate the validity of the comparisons.

The calculations for energy versus GFA residuals are presented in Table 4 and cost versus GFA residuals in Table 5. The energy versus cost scatter plots and regression details for each of total project, capital and operating data are shown in Figures 4, 5 and 6 respectively. The discovered correlation between energy and cost after eliminating any dependency on GFA is determined, and in each case the relationship has a $p$-value less than 0.05 (95\% confidence level) and a sufficiently large $t$-statistic. Parametric line of best fit has been used in this analysis. However, a nonparametric line of best fit yields very similar results. In each case, a strong relationship between energy and cost, independent of GFA, has been proven. The $r^{2}$ value for total project energy and total project cost is 0.5959 . The $r^{2}$ value for embodied energy and capital cost is 0.7081 . The $r^{2}$ value for operating energy and operating cost is 0.6264 .

\section{DISCUSSION}

In all observed instances, whether at project, elemental group or element levels, higher energy values give rise to higher costs and vice versa. This is obvious, but in addition it has been shown that cost is a strong predictor of energy. While at the work item level it is feasible to spend more capital to purchase materials or systems
Figure 1: Total project energy $v$ cost correlation

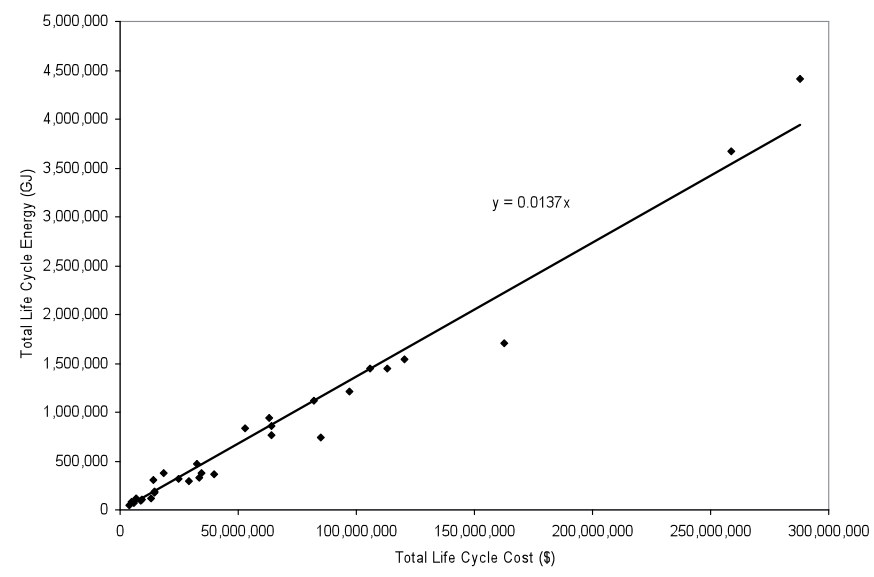

Figure 2: Embodied energy v capital cost correlation

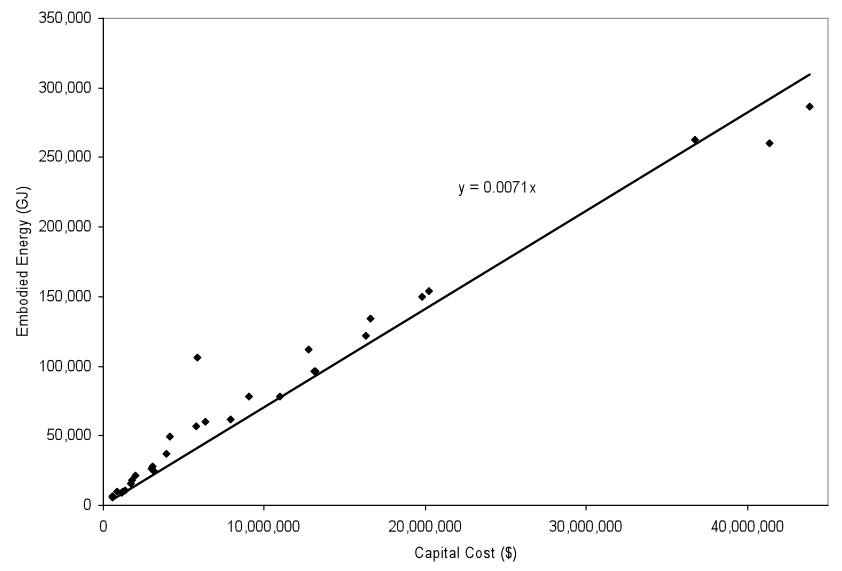

Figure 3: Operating energy v operating cost correlation

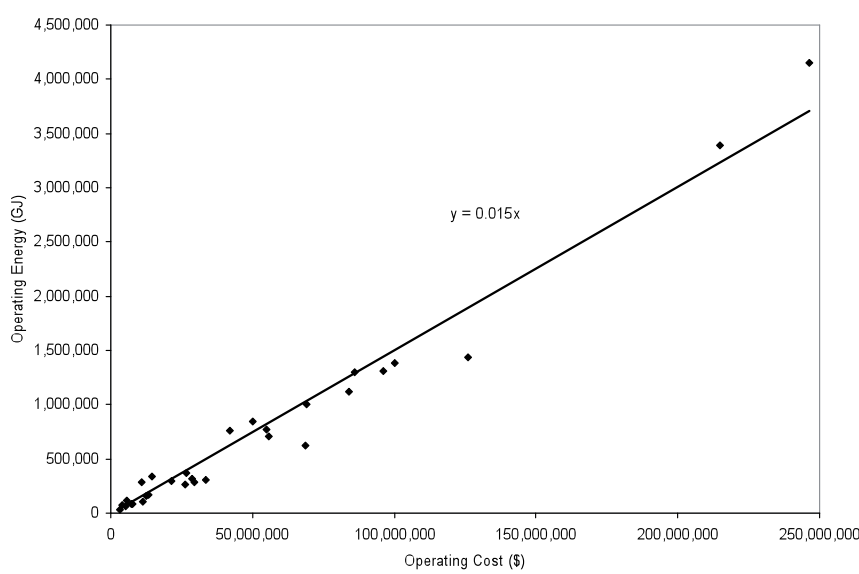


with lower embodied and/or operating energy demand, and thus introduce efficiency and value for money, at the higher levels of aggregation this is unlikely to be significant.

This finding leads to the conclusion that optimisation of energy and optimisation of cost are not mutually exclusive goals. The very strong correlations between energy and cost, and particularly between embodied energy and capital cost, suggest that this bond cannot be upset by individual decisions made at more refined levels of detail. It therefore may be more important to look elsewhere for efficiencies. In the case of embodied energy, savings can be found by building less. This may arise from more efficient floor plans (i.e. less non-functional area), more efficient plan shape (i.e. lower wall/floor ratios), more efficient internal layouts (i.e. more open plan design), and higher floor densities (i.e. people $/ \mathrm{m}^{2}$ ). In the case of operating energy, savings can be found, in addition to building less, by reducing demand through use of natural lighting and ventilation, proper orientation, reduced operating hours (where possible) and intelligent control systems.

Having said that, this paper comprises case studies that did not have significant components of recycled or reused materials. Clearly where this is achieved, initial embodied energy can be markedly reduced since the upstream energy impacts would have been previously counted on another project (i.e. double counting is not valid). The cost of recycled and reused materials varies widely (for example, refer Treloar et al., 2003). In some cases the cost can be higher than comparable new materials, and in many other cases the cost can be lower. The introduction of significant amounts of recycled and reused materials may upset the relationships found in this paper.

This issue also has implications for energy unit rates. In this paper $73.3 \%$ of projects represent new construction, and the remainder represent redevelopment projects. In many cases, redevelopment implies reuse of structure and other elements, so both embodied energy and capital cost are reduced. There is no discernible difference between the results for new and redeveloped projects, indicating that the inherent energy-cost relationship still appears to apply.

Current preoccupation with operating energy performance in Australia should be tempered with the understanding that embodied energy is significant, particularly in the context of a building's economic life, which is much less than the one-hundredyear time horizon adopted in this paper. Energy rating schemes should take embodied energy into account, simply by taking cost into account. Where the cost is high it is assumed the embodied energy is also. High performance in energy will then be dictated, at least in part, by the scale of the development. Large houses, for example, would be less likely to achieve high-energy performance than small houses, even though on a per-square-metre-basis the former are more efficient. This is a challenge for government authorities and policy makers.

Table 4: Case study energy residual summary

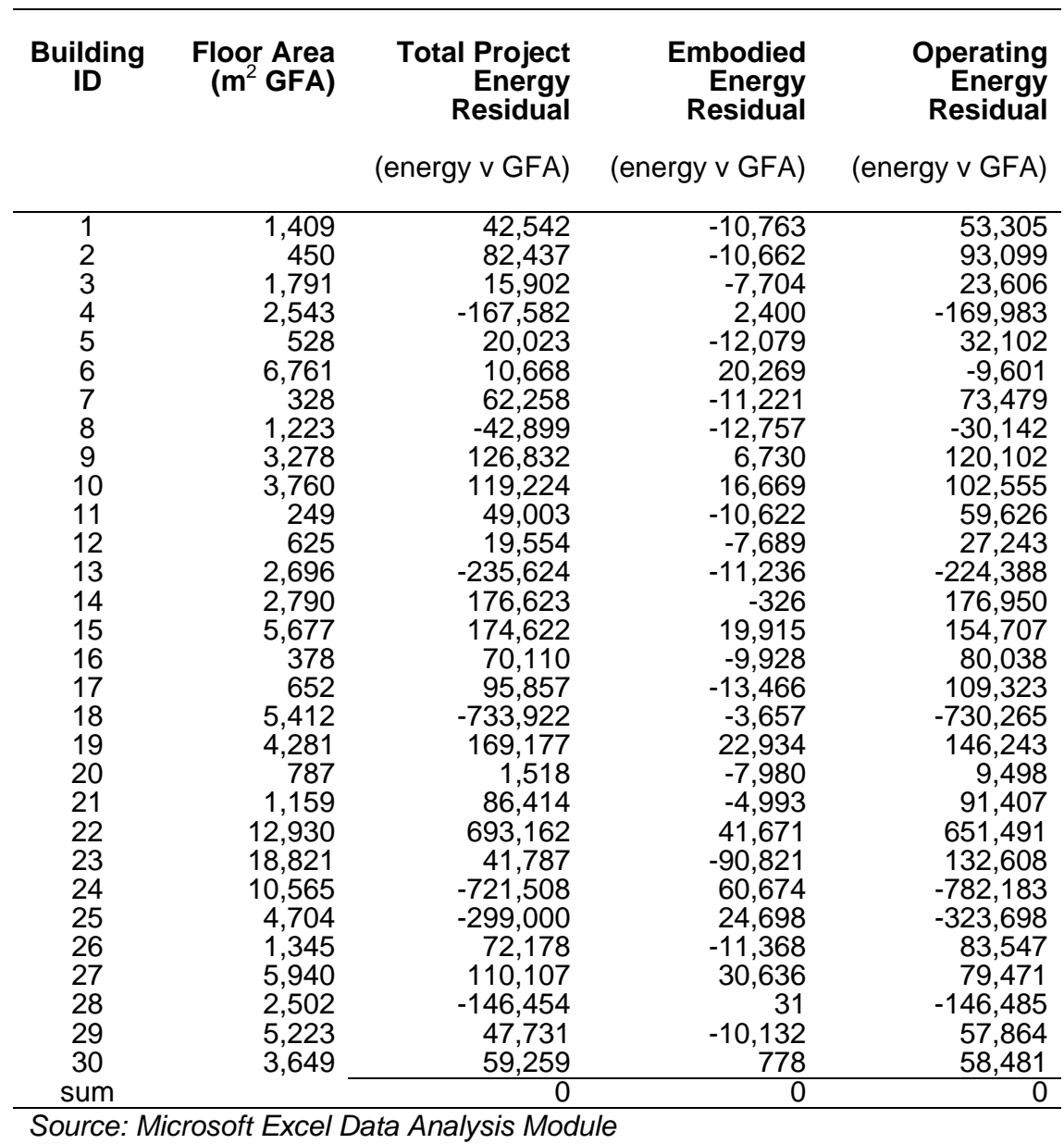


Table 5: Case study cost residual summary

\begin{tabular}{|c|c|c|c|c|}
\hline $\begin{array}{l}\text { Building } \\
\text { ID }\end{array}$ & $\begin{array}{r}\text { Floor Area } \\
\left(\mathrm{m}^{2} \text { GFA }\right)\end{array}$ & $\begin{array}{r}\text { Total Project } \\
\text { Cost Residual } \\
(\text { cost v GFA) }\end{array}$ & $\begin{array}{r}\text { Capital Cost } \\
\text { Residual } \\
\text { (cost v GFA) }\end{array}$ & $\begin{array}{r}\text { Operating Cost } \\
\text { Residual } \\
\text { (cost v GFA) }\end{array}$ \\
\hline $\begin{array}{c}1 \\
2 \\
3 \\
4 \\
5 \\
6 \\
7 \\
8 \\
9 \\
10 \\
11 \\
12 \\
13 \\
14 \\
15 \\
16 \\
17 \\
18 \\
19 \\
20 \\
21 \\
22 \\
23 \\
24 \\
25 \\
26 \\
27 \\
28 \\
29 \\
30\end{array}$ & $\begin{array}{r}1,409 \\
450 \\
1,791 \\
2,543 \\
528 \\
6,761 \\
328 \\
1,223 \\
3,278 \\
3,760 \\
249 \\
625 \\
2,696 \\
2,790 \\
5,677 \\
378 \\
652 \\
5,412 \\
4,281 \\
787 \\
1,159 \\
12,930 \\
18,821 \\
10,565 \\
4,704 \\
1,345 \\
5,940 \\
2,502 \\
5,223 \\
3,649\end{array}$ & $\begin{array}{r}-9,518,138 \\
-493,883 \\
-11,314,548 \\
-2,257,512 \\
-3,754,377 \\
8,263,047 \\
422,964 \\
-5,893,653 \\
-1,343,587 \\
750,046 \\
-524,859 \\
-1,269,675 \\
-11,053,979 \\
17,543,422 \\
18,764,069 \\
2,429,078 \\
3,781,111 \\
-57,050,080 \\
11,008,144 \\
-37,609 \\
9,960,442 \\
44,429,824 \\
-24,294,944 \\
-12,467,150 \\
7,143,334 \\
2,389,482 \\
7,326,774 \\
-7,100,107 \\
10,569,645 \\
3,592,718\end{array}$ & $\begin{array}{r}-872,695 \\
-49,275 \\
-1,035,967 \\
-653,669 \\
-628,429 \\
1,697,239 \\
-338,359 \\
-1,378,904 \\
1,946,215 \\
2,883,499 \\
-120,265 \\
-16,133 \\
-3,252,478 \\
250,413 \\
1,053,236 \\
123,610 \\
-474,917 \\
-8,967,066 \\
1,024,287 \\
-363,800 \\
-144,994 \\
8,443,003 \\
-10,122,940 \\
7,825,548 \\
3,440,533 \\
-553,181 \\
3,508,920 \\
-1,066,509 \\
-1,188,302 \\
-968,621\end{array}$ & $\begin{array}{r}-8,645,443 \\
-444,608 \\
-10,278,581 \\
-1,603,843 \\
-3,125,948 \\
6,565,807 \\
761,323 \\
-4,514,749 \\
-3,289,802 \\
-2,133,453 \\
-404,594 \\
-1,253,542 \\
-7,801,502 \\
17,293,009 \\
17,710,833 \\
2,305,468 \\
4,256,027 \\
-48,083,013 \\
9,983,857 \\
326,192 \\
10,105,436 \\
35,986,821 \\
-14,172,004 \\
-20,292,697 \\
3,702,802 \\
2,942,662 \\
3,817,854 \\
-6,033,598 \\
11,757,947 \\
4,561,339\end{array}$ \\
\hline sum & & 0 & 0 & 0 \\
\hline
\end{tabular}

Figure 4: Total project energy $\mathrm{v}$ cost residual correlation

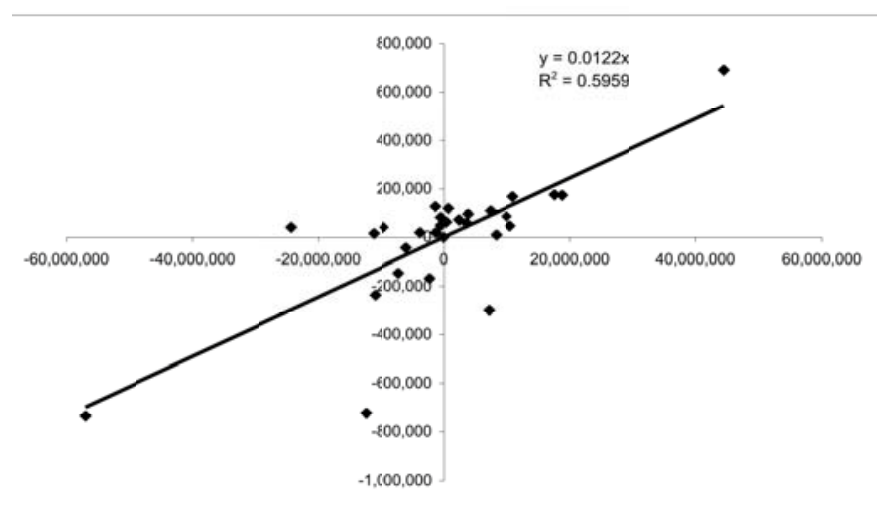

Figure 5: Embodied energy v capital cost residual correlation

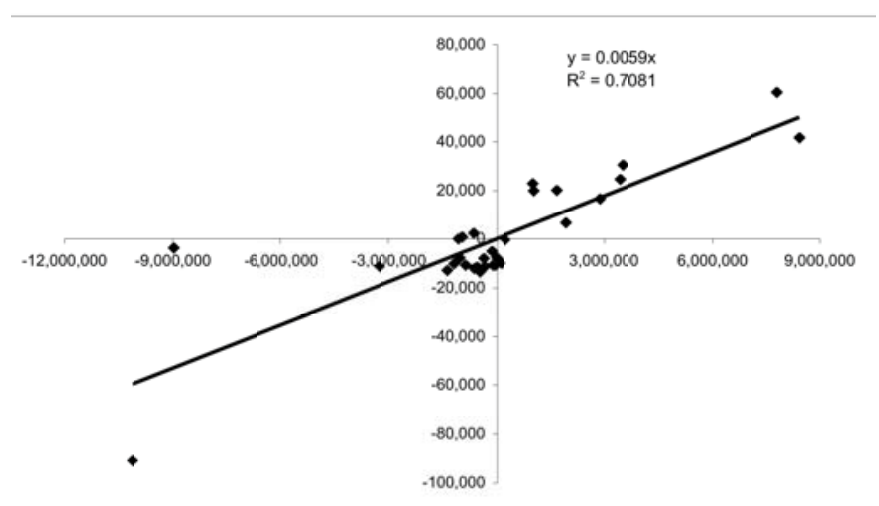

Figure 6: Operating energy v operating cost residual correlation

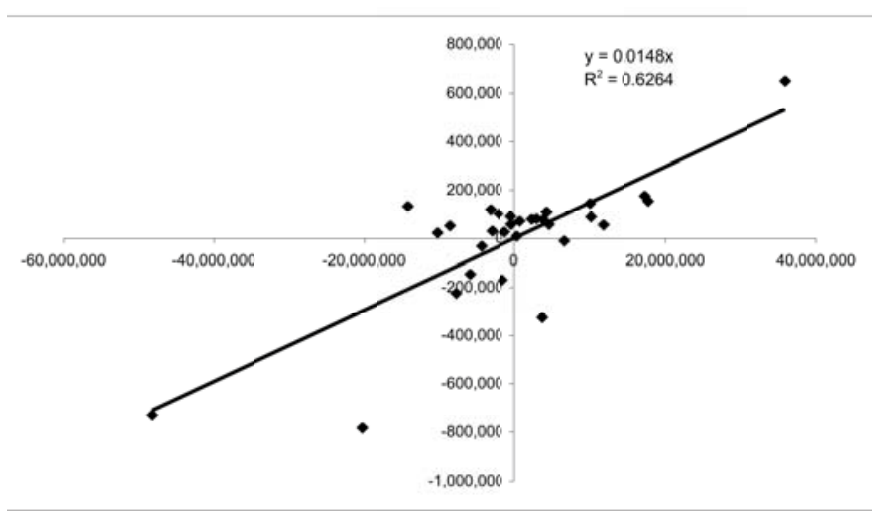


Sustainable development is a balance between progress and conservation, and most popularly defined as meeting the needs of the present generation without disadvantaging the ability of future generations to meet their own needs. But it can never be achieved. It is more likely to be approached by building less than building more. It is also important to maximise building life through adaptive reuse and recycling. Initial embodied energy, just like capital cost, is an indicator of project scope, and can be used therefore to gauge the impact of developments on the natural environment.

The lack of public knowledge about embodied energy has led to its absence from design decision-making and government policies. This situation has arisen as a direct result of the complexity of the calculations and the lack of reliable data upon which to base them. Over time, embodied energy models have become even more complex. This translates into specialist knowledge requirements and a considerable time commitment. The way forward is to develop models that practitioners can use and apply routinely to their projects. Only by putting useful tools into the hands of building designers and managers can a wider understanding of the importance of embodied energy be gained. This also enables life cycle energy and GGE calculation to be incorporated in the early design stages to reduce unnecessary environmental degradation.

\section{CONCLUSION}

The research objective was to discover the nature of the energycost relationship and other related heuristic rules by performing a thorough statistical analysis of the created dataset. This analysis included both initial and recurrent energy and cost considerations. Through a series of regression analyses, energy and cost are shown to have a high correlation, to the extent where an inherent relationship can be confidently claimed. While a dependency between energy and area, or between cost and area, has been shown to exist, after elimination of GFA using energy and cost residuals a strong correlation remains. The $r^{2}$ value for total project energy and total project cost is 0.5959 . The $r^{2}$ value for embodied energy and capital cost is 0.7081 . The $r^{2}$ value for operating energy and operating cost is 0.6264 .

The overall relationship between embodied energy and capital cost can lead to the development of predictive models for energy based on cost. For example, embodied energy is given by the regression line $y=0.0071 x$, where energy $(y)$ is expressed in $G J$ and cost $(x)$ is expressed in fourth quarter 2006 dollars. In this case it is therefore possible, by calculating construction cost (excluding contingencies, professional fees, land acquisition costs and goods and services tax), to derive embodied energy (including direct and indirect energy flows) at the project level.

But it should be remembered that this research was based on thirty 'ordinary' buildings. They had no special significance in terms of environmental performance or efficiency. They are representative of probably $90 \%$ of the existing commercial building stock in our cities. The challenge from this research, therefore, lies in trying to break the inherent energy-cost relationship by finding ways to minimise energy for new development even though the cost may have to rise. The heuristics promoted in this research apply where we make no effort to introduce improvements through innovation and better environmental design but rather follow traditional paradigms. Our ability to redefine the energy-cost relationship will ultimately be our success in realising more sustainable development.

In the developed world, where wants are routinely placed ahead of needs, the goal of sustainable development seems forlorn. The marketplace will to some extent limit the use of energy as long as energy is appropriately priced. While it might be argued that development is important to meet present needs, this must be tempered with a regard for future generations and the legacy we leave them.

\section{ACKNOWLEDGEMENTS}

The authors of this paper would like to thank the kind assistance of the late Dr Graham Treloar for the use of his input-outputbased hybrid method for embodied energy analyses and for his supervisory advice and guidance in this research, Computerelation Australia Pty Limited for making available LIFECOST ${ }^{\mathrm{TM}}$ software for operating cost analyses, and Davis Langdon Australia for permission to use their data in the case studies. Without their cooperation this research would not have been possible. Finally, the expert input from $\mathrm{Dr}$ John Boland (University of South Australia) and Professor Gerry Quinn (Deakin University) in relation to residual regression analysis is gratefully appreciated and acknowledged.

\section{REFERENCES}

Arnold F. (1993) 'Life cycle doesn't work', The Environmental Forum, September/October, 19-23.

ASEC (2001) Australia 2001: State of the environment, Independent Report to the Commonwealth Minister for the Environment and Heritage, Australian State of the Environment Committee.

Ashworth A. (1988) 'Making life cycle costing work', Chartered Quantity Surveyor, April, 17-18.

Beggs C. (2002) Energy: Management, supply and conservation, Butterworth-Heinemann.

Brown R.J. and Yanuck R.R. (1985) Introduction to life lycle costing, Prentice Hall.

\section{Bull J.W. (ed.) (1992) Life cycle costing for construction, Spon} Press.

Costanza R. (1980) 'Embodied energy and economic valuation', Science, 210, 12 December, 1219-1224.

Costanza R. (1984) 'Embodied energy and economic value in the United States economy: 1963, 1967 and 1972', Resources and Energy, 6, 129-163.

Crawford R.H. (2004) 'Using input-output data in life cycle inventory analysis', Doctor of Philosophy Thesis, Deakin University, Geelong, Australia.

Dell'Isola A.J. and Kirk S.J. (1995) Life cycle cost data, McGrawHill.

Ding G. (2004) 'The development of a multi-criteria approach for the measurement of sustainable performance for built projects and facilities', Doctor of Philosophy Thesis, University of Technology, Sydney, Australia.

Evans R., Haste N., Jones A. and Haryott R. (1998) The long term costs of owning and using buildings, London: Royal Academy of Engineering. 
Feagin J., Orum A. and Sjoberg G. eds. (1991) A case for case study, University of North Carolina Press.

Flanagan R. and Norman G. (1983) Life cycle costing for construction, Surveyors Publications.

Fuller R. (1982), 'Life cycle costing: A comprehensive approach', in Building cost techniques: New directions, P.S. Brandon ed., E. \& F.N. Spon, 439-446.

Irurah D.K. and Holm D. (1999) 'Energy impacts of building construction as applied to South Africa', Construction Management and Economics, 17, 363-374.

Kirk S.J. and Dell'Isola A.J. (1995) Life cycle costing for design professionals, McGraw-Hill.

Langston C.A. (1991) The measurement of life-costs, Sydney: Public Works Department of New South Wales.

Langston C.A. (2005) Life-cost approach to building evaluation, Elsevier.

Langston Y.L. (2006) 'Embodied energy modelling of individual buildings in Melbourne: The inherent energy-cost relationship', Doctor of Philosophy thesis, Deakin University, Geelong, Australia.

Langston Y.L and Langston C.A. (2007) 'Building energy and cost performance: An analysis of thirty Melbourne case studies', Australasian Journal of Construction Economics and Building, 7(1), 1-18.

Langston Y.L. and Langston, C.A. (2008) 'Reliability of building embodied energy modelling: An analysis of thirty Melbourne case studies', Construction Management and Economics, 26(2), 147160.

Langston C.A. and Lauge-Kristensen R. (2002) Strategic management of built facilities, Butterworth-Heinemann.

Lavine M.J. and Butler T.J. (1982) Use of embodied energy values to price environmental factors: Examining the embodied energy/dollar relationship, report no.NSF/PRA-82046, Ithaca, New York.

Oka T., Suzuki M. and Konnya T. (1993) 'The estimation of energy consumption and amount pollutants due to the construction of buildings', Energy and Buildings, 19, 303-311.

PCA (2001) Energy guidelines, Brisbane: Property Council of Australia.

Robertson G. (1991) 'Energy efficient commercial buildings: A realistic market objective', Architectural Science Review, 34, 139-142.

Stone P.A. (1960) 'The economics of building design', Journal of the Royal Society, 123(3), 237-273.

Tellis W (1997) 'Application of a case study', The Qualitative Report, 3(3), available at http://www.nova.edu/ssss/QR/QR3-3/ tellis2.html.
Treloar G.J. (1998) 'A comprehensive embodied energy analysis framework', Doctor of Philosophy Thesis, Deakin University, Geelong, Australia.

Treloar G.J., Gupta H., Love P.E.D. and Nguyen B. (2003) 'An analysis of factors influencing waste minimisation and use of recycled materials for the construction of residential buildings', Management of Environmental Quality, 14(1), 134-145.

Treloar G.J., llozor B.D. and Crawford R.H. (2002) 'Modelling energy use and greenhouse gas emissions associated with commercial building construction', in proceedings of 36th Annual Conference of the Australian and New Zealand Architectural Science Association (ANZAScA): The modern practice of architectural ccience from pedagogy to andragogy?, Geelong, Victoria, Australia, November, 533-540.

van Pelt M.J.F., Kuyvenhoven A. and Nijkamp P. (1990) 'Project appraisal and sustainability: Methodological challenges', Project Appraisal, 5, 139-158.

Verbeek I. and Wibberley L. (1996) 'Data collection', in proceedings of 1st National Conference on LCA, 29 September-1 March. 